\title{
The Impact of a Mindfulness-Based Intervention on Happiness: A Reflection on the Relevance of Integrating a Positive Psychology Framework within Mindfulness Research in Youth
}

\author{
Catherine Malboeuf-Hurtubise ${ }^{1,2}$. \\ Geneviève Taylor $^{2,3}$ • David Lefrançois ${ }^{1}$ • \\ Ilia Essopos $^{3}$ - Eric Lacourse ${ }^{4}$
}

\begin{abstract}
Mindfulness-based interventions (MBIs) are increasingly implemented in school settings to alleviate psychological distress in elementary and high school students. Recently, authors have brought forward the fact that the focus and aims of MBIs in clinical settings are largely placed on reducing negative variables and symptoms associated to mental health disorders. Thus, these may not allow us to fully understand how and in which contexts MBIs can be useful in adult populations. As MBIs aim to
\end{abstract}

Catherine Malboeuf-Hurtubise

catherine.malboeuf-hurtubise@uqo.ca

Geneviève Taylor

taylor.genevieve@uqam.ca

David Lefrançois

david.lefrancois@uqo.ca

Ilia Essopos

essopos.ilia@uqam.ca

Eric Lacourse

eric.lacourse@umontreal.ca

1 Department of Educational Sciences, Université du Québec en Outaouais, C.P. 1250, succursale Hull, Gatineau, Québec J8X 3X7, Canada

2 Research Unit on Mindfulness, Montréal, Canada

3 Department of Education and Pedagogy, Université du Québec à Montréal, C.P. 8888, Succ. Centre-Ville, Montréal, QC H3C 3P8, Canada

4 Department of Sociology, Université de Montréal, C.P. 6128, succursale Centre-ville, Montréal, Québec H3C 3J7, Canada 
help people bring focus to the present moment and awareness to all aspects of experience, both the positive and the negative, it appears relevant to study their potential to improve on positive variables, such as happiness. This paper aims to engage in a reflection on the relevance of incorporating a positive psychology framework within MBI research in youth. Specifically, the importance of measuring the impact of MBIs on positive variables such as happiness are discussed. In order to do so, a case study in which the impact of a MBI on happiness was evaluated on Mike, a third-grade elementary school student with major depressive disorder, is presented. Ten assessment time-points were used in this project ( 3 pre-intervention, 4 during the intervention and 3 post-intervention). In accordance with our initial hypothesis, the MBI had a positive impact on Mike's happiness scores at follow-up, although he still met the diagnostic criteria for major depressive disorder at post-intervention. In light of these results, it is possible that the MBI was more useful in allowing Mike to live in the present moment and to notice positive events in his life, leading him to increased happiness levels, rather than impacting directly on his depressive symptoms. Results from this case study lend support to this hypothesis and underlies the relevance of incorporating both negative and positive variables when studying the impact of MBIs in youth.

Keywords Mindfulness-based interventions · Positive psychology · Happiness · Depression · School psychology

The future of our society depends on the successful development of youth. A prerequisite for this is that youth develop practices that lead them to a satisfying, happy life. Living a happy life has been a fundamental aim and a recurring theme in Western philosophy, from Aristotle to Spinoza and Epicurus (Dahlsgaard et al. 2005). In psychology, past research has shown that happiness is an essential component of psychological adjustment and of optimal levels of functioning (Diener 2000). Happy individuals have been shown to benefit from their happiness in multiple spheres: 1) interpersonal (experiencing stronger social support and more rewarding personal relationships with friends and loved ones), 2) physical (having a strengthened immune system and living longer), and 3) financial (profiting from higher incomes and higher productivity at work) (Lyubomirsky et al. 2005). Research also shows that these benefits extend to self-regulatory and coping abilities. Communities also profit from individuals' happiness - happy people are relatively more cooperative, prosocial and focused on others (Kasser and Ryan 1996). Happiness thus seems to lead to greater overall success for individuals as well as communities. In light of the important role that happiness plays on flourishing in multiple aspects of life, it appears crucial to identify interventions that can actively boost happiness levels both in adults and in youth. The present article examines the impact of a mindfulness-based intervention on happiness using a singlecase research design and aims to engage a reflection on the relevance and importance of integrating a positive psychology framework within mindfulness research in youth.

Mindfulness-based interventions (MBIs) appear promising in helping individuals boost their happiness. So far, they have been increasingly implemented in school settings to alleviate psychological distress in elementary and high school students. Mindfulness is defined as the process by which we "[...pay] attention in a particular way: on purpose, in the present moment, and nonjudgmentally" (Kabat-Zinn 1994). It 
concerns all aspects of experience, be they pleasant or unpleasant, positive or negative. Preliminary evidence suggests that MBIs hold their promises in alleviating anxiety and depression while fostering better resilience to stress in youth (Taylor and MalboeufHurtubise 2016; Zenner et al. 2013). Specifically, past research has indicated that MBIs have a significant impact on behavioral problems, sustained attention in the classroom and emotional regulation skills in school settings (Black and Fernando 2013; Black et al. 2009; Felver et al. 2013; Flook et al. 2015; Schonert-Reichl and Lawlor 2010; Schonert-Reichl et al. 2015; Wisner 2014).

MBI research in youth has gained tremendous popularity in recent years, leading to a significant increase in the number of articles published in this field. A number of these articles have reported contradictory and/or inconclusive results in terms of the effectiveness of MBIs for children and adolescents (Britton et al. 2014; Malboeuf-Hurtubise et al. 2015a). In a recent study by Britton et al. (2014), sixth-grade students did not show statistically significant improvements on various mental health indices when compared to students in the control group, although results suggested a significant impact of the MBI on suicidal ideation. Results from a meta-analysis indicate that MBIs have a limited impact when compared to cognitive-behavioral therapy and that they are more effective in reducing the burden of psychological difficulties in youth with a mental health diagnosis than in youth displaying symptoms in the sub-clinical range (Zoogman et al. 2014). Recently, authors have brought forward the fact that the focus and aims of MBIs in clinical settings are largely placed on reducing negative variables and symptoms associated to mental health disorders (Ivtzan 2016). Thus, these may not allow us to fully understand how and in which contexts MBIs can be useful in adult populations. A similar gap can be noted in the literature on the effectiveness of MBIs in clinical settings for youth.

\section{MBIs and Positive Psychology}

Positive psychology is the study of "what makes life most worth living. It is a call for psychological science and practice to be as concerned with strength as with weakness; as interested in building the best things in life as in repairing the worst; and as concerned with making the lives of normal people fulfilling as with healing pathology" (Peterson 2009). Within a positive psychology framework, well-being is not equal to the absence of mental illness. For instance, a study by Ruini et al. (2003) showed that well-being scores did not strongly predict psychological distress scores in healthy adults, and vice-versa. Thus, well-being and distress are not incompatible and can coexist (Lomas and Ivtzan 2015).

As MBIs aim to help people bring focus to the present moment and awareness to all aspects of experience, both the positive and the negative, it appears relevant to study their potential to improve positive variables, such as happiness, meaning and well-being (Ivtzan et al. 2016; Kabat-Zinn 2003). Happiness, also referred to as subjective wellbeing, is generally defined as a state in which individuals experience positive emotions such as joy, contentment and love, along with feeling satisfied with their lives (Lyubomirsky and Lepper 1999). Psychological, or eudaimonic, well-being, is thought to be a more complex construct including concepts related to "...living a meaningful, selfrealized and fully functional life" (Ivtzan 2016; Ryff and Keyes 1995). Namely, concepts pertaining to autonomy, self-acceptance, purpose in life, environmental mastery, positive 
relationships and personal growth are included in the broader construct of psychological well-being (Ryff and Singer 2013). Happiness can thus be considered to be a component of this broader concept of psychological or eudaimonic well-being.

Brown and Ryan (2003) have argued that mindfulness may promote well-being through both direct and indirect pathways. First, mindfulness may add direct clarity and richness to one's present experience while facilitating closer, moment-to-moment contact with sensations, without the filter of discriminatory, judgmental thought. Second, mindfulness may indirectly facilitate well-being by improving self-regulated functions that are brought by ongoing attention to psychological, somatic and environmental cues (Baumeister et al. 1994).

In recent years, a growing number of studies has investigated the links between mindfulness and positive variables. For the purposes of this article, only a subset of these studies is reviewed in the following section. These globally point to a positive impact of MBIs on well-being, as broadly defined (e.g. positive affect, happiness, emotional regulation skills, autonomy and meaning) (Brown et al. 2007; Chang et al. 2015; Choi et al. 2012; Ivtzan et al. 2016). Being in a mindful state has been linked to greater well-being in adults, leading to higher levels of happiness, positive affect, selfregulation and autonomous behavior (Brown and Ryan 2003; Friese and Hofmann 2016; Lau et al. 2006). Results from a randomized controlled trial showed that teachers demonstrated higher levels of mindfulness, teaching self-efficacy in teaching, increased well-being (as measured by the presence of positive and negative affect, emotional regulation skills, depression symptoms and physical symptoms) and lower levels of burnout following a MBI, when compared to wait-list controls (Jennings et al. 2013). Furthermore, Choi et al. (2012) reported that following a MBI, both novice and experienced meditators looked happier when rated by outside observers, in comparison to participants in the control group. Results from a randomized controlled trial indicated that a smartphone-based MBI significantly increased positive affect and decreased depressive symptoms in a sample of happiness seeking adults (Howells et al. 2016). A recent study by Ivtzan et al. (2016) showed a positive impact of a MBI on well-being (namely positive emotions, self-compassion, happiness, autonomy, self-efficacy, meaning and compassion to others), while reducing depression and stress symptoms. Results were maintained at follow-up. Finally, a randomized controlled trial conducted with elementary school students showed a positive impact of a MBI on empathy, perspective taking, emotion regulation skills, optimism and depressive symptoms, when compared to children in an active control group (Schonert-Reichl et al. 2015). However, to date, no published article has evaluated the impact of a MBI on positive variables in children and adolescents with mental health disorders.

\section{Present Study}

This paper aims to engage in a reflection on the relevance of incorporating a positive psychology framework within MBI research in youth. Specifically, the importance of measuring the impact of MBIs on positive variables such as happiness are discussed. In order to do so, we present a case study, in which the impact of a MBI on happiness and depression was evaluated on a third-grade elementary school student with major depressive disorder. A single case design is used to document the effectiveness of the 
intervention over a three-month follow-up period. Ten assessment time-points were used in this project ( 3 pre-intervention, 4 during the intervention and 3 post-intervention). We hypothesized that our MBI would have a significant effect on increasing happiness scores and decreasing depression scores in our participant. Specifically, we hypothesized that happiness scores would be higher and depression scores would be lower at the end of the intervention phase when compared to the baseline phase. Improvements would be maintained during the three months' follow-up period.

\section{Method}

An experimental A-B-A single-case design was used. This design was chosen as a methodologically sound, experimental alternative to studies with larger sample sizes, in order to help measure the amplitude of change by means of regularly scheduled assessments throughout the intervention (Malboeuf-Hurtubise et al. 2015b). This study was conducted in collaboration with a school board from Montreal, Canada. Ethics approval was obtained from all institutions involved. Informed consent was obtained from our participant and from his parents.

\section{Participants}

Mike, a third-grade, nine-year old elementary school student, attending a regular classroom, participated in this study. Mike is of Hispanic descent and his mother tongue is Spanish, although he is fluent in French. He attended a francophone elementary school in the underprivileged neighborhood of Montreal-North, in Montreal, Canada. He was referred by the school psychology service to take part in this study. He had previously received a psychological diagnosis for major depressive disorder based on diagnostic criteria from the DSM-5 (American Psychiatric Association 2013), was experiencing persistent psychosocial adjustment difficulties in school and had been assessed by a psychologist to confirm the presence of a psychological diagnosis. He was not taking any form of medication to treat psychological symptoms at the time of this study. He also had a diagnosis of severe speech pathology, which had been diagnosed by a certified speech therapist. At the time of referral, Mike was in danger of repeating his school year because of his overall grades.

\section{Mindfulness-Based Intervention for This Study}

This intervention was adapted from previous work done by the first author with children and adolescents (Malboeuf-Hurtubise et al. 2013). The first author of this article, a trained therapist in MBI with previous experience with groups in pediatric oncology and school psychology, led the intervention. The MBI lasted eight weeks and was inspired from previous work in Mindfulness-Based Cognitive Therapy (MalboeufHurtubise et al. 2017; Segal et al. 2012). Mindfulness sessions occurred once a week and lasted $60 \mathrm{~min}$, in order to fit one daily classroom period and to offer a developmentally appropriate intervention specifically targeted to match Mike's shorter attention 
span. Weekly sessions included introduction to mindful eating, body scan and breathing meditations, along with the observation of thoughts, physical sensations and emotions. Homework was assigned every week, and home practice was required at least once a week. Guided meditations were recorded and a copy was given to Mike for home practice. Discussions regarding homework and home practice completion were held at the beginning of each session to monitor treatment adherence.

\section{Measures}

Subjective Happiness Scale (SHS) This measure was used to evaluate Mike's perceived happiness (Lyubomirsky and Lepper 1999). It presents high internal consistency $(\alpha=0.79-0.94)$ and good construct validity $(\alpha=0.85)$. The measure has already been used with elementary school children (Holder et al. 2010). All four items of this scale were used in this project. Mike was asked to rate on a 7-point Likert scale (from $1=n o t$ a very happy person to $7=a$ very happy person) items such as "Some people are generally very happy. They enjoy life regardless of what is going on, getting the most out of everything. To what extent does this characterization describe you?". A higher score on this measure indicates a higher level of subjective happiness.

Behavior Assessment System for Children, Second Edition (Basc-II) - Self-Report Form, Depression Scale This measure was used to evaluate depressive symptoms in Mike. This measure presents good inter-rater agreement $(r=0.53-0.74)$ and test-retest reliability $(r=0.7-0.8)$, along with high internal consistency $(\alpha=0.8-0.9)$ and clinical validity (Reynolds and Kamphaus 2004). Children are asked to evaluate statements on a 4-point Likert scale (from $0=$ never to $3=$ almost always) such as, "Nothing ever goes right for me".

\section{Assessment Time-Points}

Ten assessment time-points were included in this project. Three baseline assessments were completed during phase A (one assessment per week), four assessments were completed during the active treatment phase B (one assessment every two weeks in order to allow Mike to acquire and practice new skills) and three assessments were taken during the follow-up phase A (one assessment per month).

\section{Data Analysis}

Methods of assessment in single case research designs have been the subject of ongoing debate in the past years (Smith 2012). However, although debates regarding the appropriateness and accuracy of different methods persist, recent developments in this field of research have suggested that the use of statistical analyses, when combined with visual analysis, can be useful in analyzing results of single case designs (Kratochwill et al. 2012; Shadish 2014). In this study, primary hypotheses were tested using a single case modeling strategy allowing comparisons between A-B-A phases, and their 
statistical significance. Specifically, statistical analyses were conducted using the Tau-U index, which is a regression technique using a non-overlap approach, while controlling for monotonic trends in the baseline (Parker et al. 2011; Rakap 2015). Specifically, the Tau-U index allows for analyses of variations in scores within and between each treatment phase. The Tau-U is a non-parametric approach, and is compatible with visual analysis. Scores range from 0 to 1 , with scores lower or equal to .65 representing a weak treatment effect, scores between .66 and .92 representing a moderate treatment effect and scores higher or equal to .93 representing a large treatment effect. Results from our analyses and their $p$-values are presented in Table 1. $P$-values were considered according to the $p=.05$ threshold.

\section{Visual Analysis of the Data}

Visual analysis of the data was also completed. One of the strengths of visual analysis is that it is very conservative in the evaluation of change across phases (Barlow et al. 2009). Stable levels of target behavior need to be established before the onset of an intervention phase. In addition, only robust changes in the direction of treatment at, or near the point of treatment can be interpreted as a basic effect. Lastly, an experimental effect is based on the observation of three basic effects at three different phases within one single case experimental design for each dependent variable (Barlow et al. 2009).

\section{Results}

\section{Happiness}

Visual analysis of Mike's pre-to-post happiness scores indicates low and somewhat stable levels of happiness throughout the baseline and intervention phases, with a clear increase in scores during the follow-up phase. Scores during the follow-up phase remain stable, indicating a long-term impact of the MBI. Graphic presentation of Mike's happiness scores can be found in Fig. 1.

Table 1 Results of the Tau-U index for changes in level between phases in happiness and depression scores

\begin{tabular}{lllll}
\hline Phases & Tau-U & $S D_{\text {Tau-U }}$ & $p$ & CI $90 \%$ \\
\hline Happiness & & & & \\
$\quad$ Baseline vs Intervention & 0.17 & 0.47 & 0.72 & $-0.61<>0.94$ \\
$\quad$ Baseline vs Follow-Up & 1.00 & 0.51 & $0.04 *$ & $0.16<>1.84$ \\
$\quad$ Intervention vs Follow-Up & 1.00 & 0.47 & $0.03 *$ & $0.23<>1.78$ \\
Depression & & & & \\
$\quad$ Baseline vs Intervention & -0.42 & 5.66 & 0.38 & $-1.19<>0.36$ \\
$\quad$ Baseline vs Follow-Up & 0.33 & 4.58 & 0.51 & $-0.36<>1.19$ \\
$\quad$ Intervention vs Follow-Up & 0.42 & 5.66 & 0.38 & $-0.50<>1.17$ \\
\hline
\end{tabular}

$* p \leq 0.05$ 


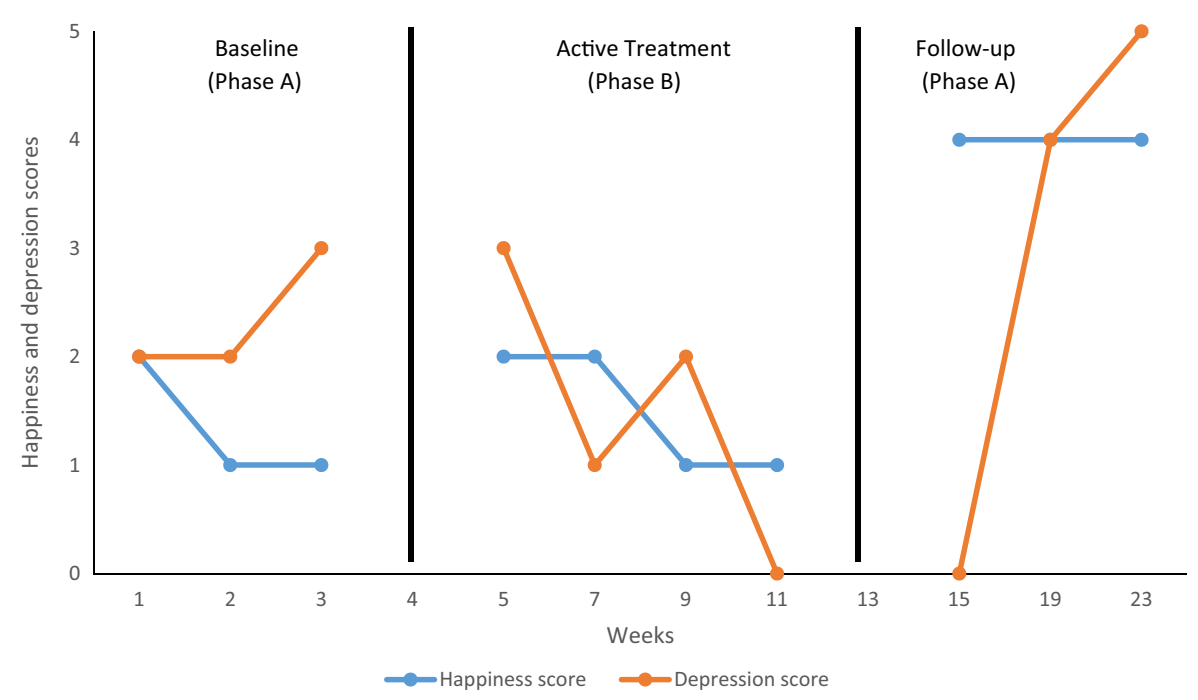

Fig. 1 Graphical display of baseline level and changes in level between consecutive phases in happiness and depression

Tau-U analyses showed significant phase differences in happiness scores between the intervention and follow-up phases, with an increase in happiness scores and a large effect size: Tau-U $=1, p=.03$. Similarly, statistical analyses showed significant phase differences in happiness scores between the baseline and follow-up phases, with an increase in happiness scores and a large effect size: Tau-U $=1, p=.04$. The model did not detect a trend in the baseline data (see Table 1).

\section{Depression}

Visual analysis of Mike's pre-to-post depression scores indicates somewhat high levels of depression symptoms at baseline, with unstable levels of symptoms occurring during the intervention phase, starting at a high level, followed by a decrease, a re-increase and a final decrease in scores during the active treatment phase. A clear and important increase in scores can be seen during the follow-up phase. Overall, Mike's scores are somewhat unpredictable, indicating the presence of ongoing depressive symptoms throughout the intervention. Graphic presentation of Mike's depression scores can be found in Fig. 1.

Tau- $U$ analyses did not show significant phase differences in depression scores between the baseline, intervention and follow-up phases. The model did not detect a trend in the baseline data (see Table 1).

Mike was reassessed by a school psychologist after completion of this study. Specifically, he was assessed immediately post-intervention, then once per month during the follow-up phase, as part of the school psychologist's therapy follow-up plan. Although significant improvements were reported both by him (e.g. feeling less sad) and by his teacher (e.g. more perseverant in his school work) in his classroom functioning and overall grades, based on DSM-5 criteria, Mike was still meeting the diagnostic criteria for major depressive disorder immediately post-intervention and at 
each assessment time-point during the follow-up period (American Psychiatric Association 2013).

\section{Additional Analyses}

The relationship between happiness and depression scores was investigated using a non-parametric Spearman Rho correlation coefficient. Results from this analysis did not show any significant correlation between these two variables $(r=0.29, p=.40)$, thus indicating that variations in happiness scores were not related to variations in depression scores.

\section{Discussion}

This article aimed to engage in a reflection on the relevance of incorporating positive variables in the study of MBIs in youth. In doing so, results from a single case study evaluating the impact of a MBI on happiness on a nine-year-old elementary school student with major depressive disorder were presented. In accordance with our initial hypothesis, the MBI had an impact on increasing Mike's happiness scores at follow-up, although he still met the diagnostic criteria for major depressive disorder at postintervention. In light of these results, it is possible that the MBI was more useful in allowing Mike to live in the present moment and to notice positive events in his life, leading him to increased happiness levels, rather than impacting directly on his depressive symptoms (Brown 2015; Brown and Ryan 2003). Our results also support those from past research in adult populations, showing that a mindful state is related to positive variables such as well-being, happiness, positive affect, self-regulation, compassion and autonomy (Brown and Ryan 2003; Friese and Hofmann 2016; Ivtzan et al. 2016; Lau et al. 2006). Finally, they complement results of Schonert-Reichl et al.'s (2015) study of elementary school children showing that a MBI increased levels of optimism, emotional regulation and empathy.

Mike's involvement in the MBI was significant from the beginning of the sessions, as he showed a marked desire to improve his condition. He would systematically practice meditations between sessions and complete given assignments, and his practice was sustained throughout the follow-up period. In class, his teacher quickly reported improvements in terms of his mood. Furthermore, discussions on the theme of mindfulness indicated that Mike reported significant changes in his abilities to notice events unfolding in the present moment (e.g., reporting he would notice and pay attention to surrounding sounds, such as ongoing noise in the classroom or cars passing by outside), and that he would act with more awareness as the sessions unfolded, thus indicating that mindfulness could explain, at least partially, the improvements observed his happiness scores.

Within the positive psychology framework, mental health is not defined as the absence of mental illness (Ivtzan 2016). The removal of mental illness does not automatically lead to the achievement of optimal functioning and of better mental health (Ryff and Singer 1998). Instead, positive psychology approaches the topic of mental health from a different angle: individuals are meant to achieve an optimal level of mental health when they are in a state of flourishing - of optimal functioning. Flourishing can be defined as a broad construct in which concepts such as an 
individual's positive emotions, engagement, relationships, meaning in life and accomplishments are taken into account (Seligman 2012). In this case study, it is possible that, following the MBI, Mike's increase in happiness levels led him to reach optimal conditions for flourishing and well-being (as evidenced by his increased happiness at follow-up), in spite of his major depressive disorder. Furthermore, given that it is not possible to live a life devoid of unpleasant and stressful events, it is possible that the MBI helped Mike increase his happiness by increasing his awareness of positive experiences and by building his resilience to stress (Wong 2011). Accordingly, past research has suggested that MBIs have an impact on well-being by bringing awareness to and enhancing the savoring of day-to-day experiences (Garland et al. 2015; Ivtzan et al. 2016; Lindsay and Creswell 2015).

Our results show a seemingly counterintuitive discrepancy between Mike's increases in happiness scores, the absence of a significant decrease in depression scores and the presence of clinically significant depressive symptoms at post-intervention. In their coactivation model of healthy coping, Larsen et al. (2003) posit that individuals facing severe stressors, such as major depressive disorder, will process higher levels of negative emotions and thoughts, and that their ratio of positive to negative emotions will be lower. In light of this model, Mike's increase in happiness scores could be indicative of the effort he had to deploy to increase his overall well-being (although this variable was not explicitly measured in the present study), albeit this effort did not impact his depressive symptoms to the point of falling below the clinical range (Wong 2011). Given the severity of his major depressive disorder, it is possible that the required adaptive effort to increase overall his well-being translated into higher happiness scores from pre-to-post intervention, but not into clinically significant decreases in depressive symptoms or statistically significant decreases in depression scores. Correspondingly, according to Larsen et al. (2003), negative and positive emotions are not opposite constructs: they are rather conceptualized as independent. Thus, increasing positive emotions such as happiness would not equal reducing negative emotions such as depressive symptoms, and vice-versa, reinforcing the idea according to which positive and negative variables should be studied together (Wong 2011). Results from this case study and from our correlation analyses lend support for this hypothesis and thus for the relevance of incorporating both negative and positive variables when studying the impact of MBIs in youth.

\section{Limitations}

The A-B-A design used in this study presents some risks in regards to internal validity (Barlow et al. 2009). Threats to internal validity are time-related factors such as history and testing effects. As the intervention was conducted during the winter, spring break vacation (first week of March) might have caused variations in mood for Mike. The follow-up period took place near the end of the school year, in the months of April, May and June, which may have also impacted our results, namely by increasing Mike's happiness scores. Nonetheless, this design allowed us to document the process of change in our participant, which in turn provides valuable information to researchers interested in developing and testing MBIs for elementary school students with mental health disorders. 
Using objective observational measures of happiness, such as outside observer ratings, would improve on this design (Choi et al. 2012). Evaluating the impact of a MBI on positive affect, rather than limiting the analysis to happiness scores alone, would also provide us with a more comprehensive portrait of the potential impact of mindfulness on positive variables in youth. Additionally, it is important to acknowledge both caregivers and teachers as possible sources of information regarding behavior change. Including such reports may help account for some self-report bias, and should be included in future projects of this sort. Finally, additional assessment time-points in each phase would strengthen the overall design and allow us to draw more robust conclusions. During the follow-up phase, these could allow to detect further improvements (or deterioration) in happiness. Although a minimum of three assessment time-points are necessary to conduct single case designs, a targeted number of five per phase has been previously recommended (Smith 2012). Furthermore, as the present study employs different time frames within its three phases (i.e. baseline, active treatment and follow-up phases), it is possible that this confounded the results of this case study to some extent. For example, the monthly assessment time-points that occurred during follow-up might have concealed more subtle changes in Mike's happiness and depressive scores once the intervention was over. Similarly, the bi-weekly data collection during the active treatment phase could have yielded somewhat different results (when compared to weekly assessment timepoints during the baseline phase), resulting in a loss of information in Mike's overall changes in happiness and depression scores. Thus, employing a uniform approach of data collection throughout phases in a future study would allow us to control for this issue. Nonetheless, it is not unusual in single case studies to report different times frames of data collection throughout phases (Graham et al. 2012). The use of a series of multiple baseline single case design, implying the study of more than one individual at a time and allowing for inter-individual comparisons, would also be beneficial in gathering more information on the impact of mindfulness interventions on positive and negative variables for youth with mental health disorders. However, at the time of conducting this project, only one student with a major depressive disorder was available in the school in which this study took place.

\section{Suggestions for Future Research}

What future awaits MBI research in youth and what research questions should researchers aim to answer in this regard? Research on adults has already investigated the link between trait and state mindfulness and positive variables, such as well-being (Brown and Ryan 2003; Choi et al. 2012; Jennings et al. 2013). However, to our knowledge, only two studies investigated the association between mindfulness and positive variables such as optimism, altruism and prosocial behavior in youth (Flook et al. 2015; Schonert-Reichl et al. 2015) and none has linked mindfulness to happiness. Evaluating such links appears crucial in order to conclude whether MBIs can help foster resilience in youth who face mental health issues. Furthermore, future studies would do well to evaluate the impact of MBIs on psychological (or eudaimonic) wellbeing rather than to rely solely on happiness, thus providing a more comprehensive portrait of how mindfulness practice can influence positive variables. Eudaimonic well- 
being is a cornerstone of self-determination theory (SDT), and is hypothesized to be directly influenced by an individual's capacity to be mindful (Ryan et al. 2013).

Using SDT to understand underlying mechanisms of mindfulness within a positive psychology framework would be useful in future studies with youth. SDT is a macrotheory of human motivation and optimal functioning that posits that the satisfaction of three basic psychological needs are at the root of well-being: the need for competence (i.e., feeling effective in one's interactions with the environment), the need for autonomy (i.e., feeling choice, volition and willingness in one's actions), and the need for relatedness (i.e., feeling connected with and loved by others) (Ryan and Deci 2000). The link between mindfulness and well-being within SDT has been explored in past research and recent findings suggest that mindfulness leads to optimal selfregulation, allowing individuals to be in touch with their needs, values and emotions (Brown and Ryan 2003; Ryan and Deci 2000). As such, mindfulness is hypothesized to lead to more realistic appraisals and higher satisfaction of the three basic psychological needs (Deci et al. 2015). In an experience-sampling study with adults, Brown and Ryan (2003) showed that state mindfulness predicted daily levels of need satisfaction as well as positive emotions. In other words, on days where people were more mindful, they experienced higher levels of need satisfaction and more positive emotions. A recent study by Chang et al. (2015) showed that basic psychological need fulfillment acted as a mediator between mindfulness and well-being in adults. However, in the vast majority of mindfulness and SDT research, mindfulness is measured as a disposition or state rather than as an acquired ability. In order to expand on this literature, experimentally manipulating participants' levels of mindfulness by training them to become more mindful, in order to evaluate its impact on well-being and on the satisfaction of basic psychological need fulfillment, would provide a clearer picture of the links between these three concepts. Incorporating philosophy for children (P4C) workshops into MBIs could also be interesting, as P4C aims to ensure selfdetermination in children (Vansieleghem and Kennedy 2011). Along the same line, future research could aim to measure self-compassion (an essential component of MBI training) in youth, especially for those with mental health disorders, as this construct has been linked to greater basic psychological need fulfillment in adults (Neff et al. 2005).

Finally, incorporating positive psychology interventions within MBIs for youth, such as gratitude or personal strength exercises, and evaluating their impact on both positive and negative variables represents an interesting avenue (Malboeuf-Hurtubise and Lacourse 2016). Recent evidence suggests that the merging of both MBI and positive psychology interventions has added benefits in adults, namely to enhance flourishing and optimal functioning (Ivtzan et al. 2016). Positive psychology interventions have also been shown to reduce depressive symptoms and increase well-being in depressed adults (Sin and Lyubomirsky 2009). As such, combining both approaches for elementary and high school students with mental health issues appears both feasible and promising.

Acknowledgements The authors wish to thank Josée Douaire, Ph.D., and Samya-Hayette Ait-Kaci-Azzou for their input on the project and assistance in its implementation. Funding for this project was provided by scholarships to the first author from the Fonds de Recherche en Société et Culture du Québec. 


\section{Compliance with Ethical Standards}

Conflict of Interest Catherine Malboeuf-Hurtubise and Eric Lacourse have released a manual on the mindfulness-based intervention described and used in this study (Midi Trente publishers). Geneviève Taylor, David Lefrançois and Ilia Essopos declare that they have no conflict of interest.

Ethical Approval All procedures performed in studies involving human participants were in accordance with the ethical standards of the institutional and/or national research committee and with the 1964 Helsinki declaration and its later amendments or comparable ethical standards.

\section{References}

American Psychiatric Association. (2013). Diagnostic and statistical manual of mental disorders : DSM-5.

Barlow, M., Nock, M., \& Hersen, M. (2009). Single case experimental designs: Strategies for studying behavior for change. Boston: Pearson / Allyn Bacon.

Baumeister, R. F., Heatherton, T. F., \& Tice, D. M. (1994). Losing control: How and why people fail at selfregulation. San Diego: Academic Press.

Black, D., \& Fernando, R. (2013). Mindfulness Training and Classroom Behavior Among Lower-Income and Ethnic Minority Elementary School Children. Journal of Child and Family Studies, 23(7), 1-5. https://doi.org/10.1007/s10826-013-9784-4.

Black, D. S., Milam, J., \& Sussman, S. (2009). Sitting-meditation interventions among youth: a review of treatment efficacy. Pediatrics, 124(3), e532-e541. https://doi.org/10.1542/peds.2008-3434.

Britton, W. B., Lepp, N. E., Niles, H. F., Rocha, T., Fisher, N. E., \& Gold, J. S. (2014). A randomized controlled pilot trial of classroom-based mindfulness meditation compared to an active control condition in sixth-grade children. Journal of School Psychology, 52(3), 263-278.

Brown, K. W. (2015). Mindfulness Training to Enhance Positive Functioning. In K. W. Brown, J. D. Creswell, \& R. M. Ryan (Eds.), Handbook of mindfulness: Theory, research, and practice. New York: Guilford Publications.

Brown, K. W., \& Ryan, R. M. (2003). The benefits of being present: mindfulness and its role in psychological well-being. Journal of Personality and Social Psychology, 84(4), 822.

Brown, K. W., Ryan, R. M., \& Creswell, J. D. (2007). Mindfulness: Theoretical foundations and evidence for its salutary effects. Psychological Inquiry, 18(4), 211-237.

Chang, J.-H., Huang, C.-L., \& Lin, Y.-C. (2015). Mindfulness, basic psychological needs fulfillment, and well-being. Journal of Happiness Studies, 16(5), 1149-1162.

Choi, Y., Karremans, J. C., \& Barendregt, H. (2012). The happy face of mindfulness: Mindfulness meditation is associated with perceptions of happiness as rated by outside observers. The Journal of Positive Psychology, 7(1), 30-35.

Dahlsgaard, K., Peterson, C., \& Seligman, M. E. (2005). Shared virtue: The convergence of valued human strengths across culture and history. Review of General Psychology, 9(3), 203.

Deci, E. L., Ryan, R. M., Schultz, P. P., \& Niemiec, C. P. (2015). Being aware and functioning fully: mindfulness and interest-taking within Self-Determination Theory. Handbook of mindfulness: Theory, research, and practice. New York: Guilford.

Diener, E. (2000). Subjective well-being: The science of happiness and a proposal for a national index. American Psychologist, 55(1), 34.

Felver, J. C., Frank, J. L., \& McEachern, A. D. (2014). Effectiveness, acceptability, and feasibility of the soles of the feet mindfulness-based intervention with elementary school students. Mindfulness, 5(5), 589-597.

Flook, L., Goldberg, S. B., Pinger, L., \& Davidson, R. J. (2015). Promoting prosocial behavior and selfregulatory skills in preschool children through a mindfulness-based kindness curriculum. Developmental Psychology, 5l(1), 44.

Friese, M., \& Hofmann, W. (2016). State mindfulness, self-regulation, and emotional experience in everyday life. Motivation Science, 2(1), 1.

Garland, E. L., Farb, N. A., Goldin, P., \& Fredrickson, B. L. (2015). Mindfulness broadens awareness and builds eudaimonic meaning: a process model of mindful positive emotion regulation. Psychological Inquiry, 26(4), 293-314. 
Graham, J. E., Karmarkar, A. M., \& Ottenbacher, K. J. (2012). Small sample research designs for evidencebased rehabilitation: Issues and methods. Archives of Physical Medicine and Rehabilitation, 93(8 Suppl), S111-S116. https://doi.org/10.1016/j.apmr.2011.12.017.

Holder, M. D., Coleman, B., \& Wallace, J. M. (2010). Spirituality, religiousness, and happiness in children aged 8-12 years. Journal of Happiness Studies, 11(2), 131-150.

Howells, A., Ivtzan, I., \& Eiroa-Orosa, F. J. (2016). Putting the 'app'in happiness: a randomised controlled trial of a Smartphone-based mindfulness intervention to enhance wellbeing. Journal of Happiness Studies, 17(1), 163-185.

Ivtzan, I. (2016). Mindfulness in positive psychology: An introduction. In I. Ivtzan \& T. Lomas (Eds.), Mindfulness in Positive Psychology: The Science of Meditation and Wellbeing (p. 1). London: Routledge.

Ivtzan, I., Young, T., Martman, J., Jeffrey, A., Lomas, T., Hart, R., \& Eiroa-Orosa, F. J. (2016). Integrating mindfulness into positive psychology: A randomised controlled trial of an online positive mindfulness program. Mindfulness, 7(6), 1396-1407.

Jennings, P. A., Frank, J. L., Snowberg, K. E., Coccia, M. A., \& Greenberg, M. T. (2013). Improving classroom learning environments by Cultivating Awareness and Resilience in Education (CARE): Results of a randomized controlled trial. School Psychology Quarterly, 28(4), 374.

Kabat-Zinn, J. (1994). Wherever you go there you are: Minfulness meditation in everyday life. New York: Hyperion.

Kabat-Zinn, J. (2003). Mindfulness-based interventions in context - past, present, and future. Clinical Psychology - Science and Practice, 10(2), 144-156.

Kasser, T., \& Ryan, R. M. (1996). Further examining the American dream: Differential correlates of intrinsic and extrinsic goals. Personality and Social Psychology Bulletin, 22(3), 280-287.

Kratochwill, T. R., Hitchcock, J. H., Horner, R. H., Levin, J. R., Odom, S. L., Rindskopf, D. M., \& Shadish, W. R. (2012). Single-case intervention research design standards. Remedial and Special Education, 0741932512452794.

Larsen, J. T., Hemenover, S. H., Norris, C. J., \& Cacioppo, J. T. (2003). Turning adversity to advantage: On the virtues of the coactivation of positive and negative emotions. A psychology of human strengths: Fundamental questions and future directions for a positive psychology, 211-225.

Lau, M. A., Bishop, S. R., Segal, Z. V., Buis, T., Anderson, N. D., Carlson, L., \& Devins, G. (2006). The Toronto mindfulness scale: Development and validation. Journal of Clinical Psychology, 62(12), 14451467.

Lindsay, E. K., \& Creswell, J. D. (2015). Back to the basics: how attention monitoring and acceptance stimulate positive growth. Psychological Inquiry, 26(4), 343-348.

Lomas, T., \& Ivtzan, I. (2015). Second wave positive psychology: exploring the positive-negative dialectics of wellbeing. Journal of Happiness Studies, 1-16.

Lyubomirsky, S., \& Lepper, H. S. (1999). A measure of subjective happiness: Preliminary reliability and construct validation. Social Indicators Research, 46(2), 137-155.

Lyubomirsky, S., King, L., \& Diener, E. (2005). The benefits of frequent positive affect: does happiness lead to success? Psychological Bulletin, 131(6), 803.

Malboeuf-Hurtubise, C., \& Lacourse, É. (2016). Mission Méditation: La présence attentive à l'école pour des élèves épanouis, concentrés et ouverts. Québec: Éditions Midi Trente.

Malboeuf-Hurtubise, C., Achille, M., Sultan, S., \& Vadnais, M. (2013). Mindfulness-based intervention for teenagers with cancer: study protocol for a randomized controlled trial. Trials, 14(1), 135.

Malboeuf-Hurtubise, C., Achille, M., Muise, L., Beauregard-Lacroix, R., Vadnais, M., \& Lacourse, É. (2016). A mindfulness-based meditation pilot study: Lessons learned on acceptability and feasibility in adolescents with cancer. Journal of Child and Family Studies, 25(4), 1168-1177.

Malboeuf-Hurtubise, C., Lacourse, E., Herba, C., Taylor, G., \& Amor, L. B. (2017). Mindfulness-based intervention in elementary school students with anxiety and depression: a series of n-of-1 trials on effects and feasibility. Journal of Evidence-Based Complementary \& Alternative Medicine. https://doi. org/10.1177/2156587217726682.

Malboeuf-Hurtubise, C., Joussemet, M., Taylor, G., \& Lacourse, E. (2017). Effects of a mindfulness-based intervention on the perception of basic psychological need satisfaction among special education students. International Journal of Disability, Development and Education, p. 1-12. https://doi.org/10.1080 /1034912X.2017.1346236.

Neff, K. D., Hsieh, Y.-P., \& Dejitterat, K. (2005). Self-compassion, achievement goals, and coping with academic failure. Self and Identity, 4(3), 263-287.

Parker, R. I., Vannest, K. J., Davis, J. L., \& Sauber, S. B. (2011). Combining nonoverlap and trend for singlecase research: Tau-U. Behavior Therapy, 42(2), 284-299. 
Peterson, C. (2009). Foreword. In C. R. Snyder \& S. J. Lopez (Eds.), Oxford handbook of positive psychology. London: Oxford University Press.

Rakap, S. (2015). Effect sizes as result interpretation aids in single-subject experimental research: description and application of four nonoverlap methods. British Journal of Special Education, 42(1), 11-33.

Reynolds, C. C., \& Kamphaus, R. W. (Eds.). (2004). The Behavior Assessment System for Children - Second Edition. San Antonio: AGS Publishing.

Ruini, C., Ottolini, F., Rafanelli, C., Tossani, E., Ryff, C. D., \& Fava, G. A. (2003). The relationship of psychological well-being to distress and personality. Psychotherapy and Psychosomatics, 72(5), 268-275.

Ryan, R. M., \& Deci, E. L. (2000). Self-determination theory and the facilitation of intrinsic motivation, social development, and well-being. American Psychologist, 55(1), 68.

Ryan, R. M., Huta, V., \& Deci, E. L. (2013). Living well: A self-determination theory perspective on eudaimonia. The Exploration of Happiness, p. 117-139. Springer Netherlands. https://doi.org/10.1007 1978-94-007-5702-8 7.

Ryff, C. D., \& Keyes, C. L. M. (1995). The structure of psychological well-being revisited. Journal of Personality and Social Psychology, 69(4), 719.

Ryff, C. D., \& Singer, B. (1998). The contours of positive human health. Psychological Inquiry, 9(1), 1-28.

Ryff, C. D., \& Singer, B. H. (2013). Know thyself and become what you are: A eudaimonic approach to psychological well-being The Exploration of Happiness, p. 97-116. Springer Netherlands. https://doi. org/10.1007/978-94-007-5702-8 6.

Schonert-Reichl, K. A., \& Lawlor, M. S. (2010). The effects of a mindfulness-based education program on pre-and early adolescents' well-being and social and emotional competence. Mindfulness, 1(3), 137-151.

Schonert-Reichl, K. A., Oberle, E., Lawlor, M. S., Abbott, D., Thomson, K., Oberlander, T. F., \& Diamond, A. (2015). Enhancing cognitive and social-emotional development through a simple-to-administer mindfulness-based school program for elementary school children: A randomized controlled trial. Developmental Psychology, 51(1), 52.

Segal, Z. V., Williams, J. M. G., \& Teasdale, J. D. (2012). Mindfulness-based cognitive therapy for depression. Toronto: Guilford Press.

Seligman, M. E. (2012). Flourish: A visionary new understanding of happiness and well-being. New York: Simon and Schuster.

Shadish, W. R. (2014). Analysis and meta-analysis of single-case designs: An introduction. Journal of School Psychology, 52(2), 109-122.

Sin, N. L., \& Lyubomirsky, S. (2009). Enhancing well-being and alleviating depressive symptoms with positive psychology interventions: A practice-friendly meta-analysis. Journal of Clinical Psychology, 65(5), 467-487.

Smith, J. D. (2012). Single-case experimental designs: A systematic review of published research and current standards. Psychological Methods, 17(4), 510.

Taylor, G., \& Malboeuf-Hurtubise, C. (2016). La présence attentive en milieu scolaire: État des connaissances et pistes de recherche pour l'avenir. In S. Grégoire, L. Lachance, \& L. Richer (Eds.), La présence attentive (mindfulness): État des connaissances théoriques, empiriques et pratiques (pp. 161-180). Québec: Presses de l'Université du Québec.

Vansieleghem, N., \& Kennedy, D. (2011). What is philosophy for children, what is philosophy with children - after Matthew Lipman? Journal of Philosophy of Education, 45(2), 171-182.

Wisner, B. L. (2014). An exploratory study of mindfulness meditation for alternative school students: perceived benefits for improving school climate and student functioning. Mindfulness, 5(6), 626-638.

Wong, P. T. (2011). Positive psychology 2.0: Towards a balanced interactive model of the good life. Canadian Psychology/Psychologie Canadienne, 52(2), 69.

Zenner, C., Herrnleben-Kurz, S., \& Walach, H. (2013). Mindfulness-based interventions in schools-a systematic review and meta-analysis. Frontiers in Psychology, 5, 603-603.

Zoogman, S., Goldberg, S. B., Hoyt, W. T., \& Miller, L. (2014). Mindfulness interventions with youth: A meta-analysis. Mindfulness, 6(2), 1-13. 